
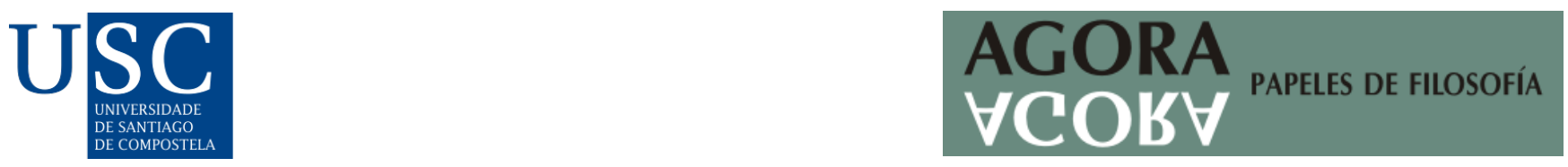

Agora. Papeles de Filosofía, 41(1), 2022. ISSN-e: 2174-3347

https://doi.org/10.15304/agora.41.1.7708

Recensiones

\title{
LEWIS, Holly: La política de todes. Feminismo, teoría queer y marxismo en la intersección, tradución de Javier Sáez del Álamo, Edicions Bellaterra, Barcelona, 2020, 323p.
}

\author{
Alexandre Pichel-Vázquez
}

Recibido: 14/05/2021; Aceptado: 21/05/2021

Catro anos despois da súa publicación orixinal, a obra de Holly Lewis The Politics of Everybody. Feminism, Queer Theory and Marxism at the Intersection (Zed Books, Londres, 2016) ten máis relevancia e forza ca nunca. A crise sanitaria producida pola pandemia da Covid-19, a perda de postos de traballo nunha sociedade aínda non recuperada da anterior crise e ao auxe da extrema dereita no estado español fai que sexa aínda máis evidente a necesidade de configurar alianzas políticas entre e dentro das clases obreiras. Este é o obxectivo principal de Lewis: configurar e construír pontes políticas e analíticas dentro da clase obreira que permitan pór a dialogar ás teorías e mobilizacións marxistas, feministas e queers.

As máis de trescentas páxinas divídense nunha introdución, tres capítulos centrais e unhas conclusións que, en conxunto, teñen a clara vocación de actualizar a teoría e a práctica marxista para poder entender como a economía, o xénero e a sexualidade son elementos co-constituíntes. Coa intención de se facer comprensíbel dentro de cada un dos mundos teóricos e prácticos que interpela, Holly Lewis utiliza o primeiro capítulo para presentar os debates actuais en Occidente sobre o xénero e a sexualidade, definir o que é o capitalismo dende as ideas marxistas e aclarar as tradicións filosóficas marxistas da teoría queer. 0 segundo capítulo é unha clase maxistral sobre a teoría marxista, o funcionamento do traballo e a configuración dunha análise materialista para entender, comprender e analizar as dinámicas sexuais e de xénero. Deste xeito, a autora non só é capaz de amosar as tensións e relacións entre o marxismo e o feminismo, senón tamén desenvolver unha análise eficaz das opresións trans e queer dende unha perspectiva feminista marxista. No terceiro capítulo, Lewis analiza as chaves para a configuración dun internacionalismo queer para todes dende o materialismo marxista. Deste xeito, lévanos placidamente cara unhas conclusións onde a autora propón un decálogo para o fortalecemento dunha posición política marxista e queer.

A pretensión política do texto de Lewis é a de servir como unha ferramenta política útil e eficaz para a esquerda política e os movementos sociais polos dereitos humanos. Cunha clara intención internacionalista, de esquerdas e para todes, Lewis navega entre a universalidade (branca e masculina) absorbente e a paranoia individualista:

El universalismo parece significar su opuesto: que las culturas soberanas son absorbidas en una cultura dominante que se presente a sí misma como el universo entero. Como respuesta a la violencia de esta marca de la política universal, ha aparecido un individualismo paranoico en el cual la familia, la comunidad, y la

Copyright $\odot$ Universidade de Santiago de Compostela. This is an open access article distributed under the terms of the Creative Commons Attribution-NonComercial-NoDerivatives 4.0 International (CC BY-NC-ND 4.0) License. 
cultura - que son formas plurales del yo— son imaginadas como el único bastión contra esa absorción en el todes que es una tapadera de un vacío (pp. 20-21).

Neste senso, Lewis apunta de forma brillante cara unha argumentación teórica e política que poida superar o universalismo ilustrado occidental, mais sen caer na paranoia individualista promulgada, defendida e traballada nos últimos anos pola dereita e extrema dereita internacional.

No primeiro dos capítulos, onde Lewis expón as bases teóricas e analíticas fundamentais da súa perspectiva marxista e queer, faise un percorrido iniciático entre os debates máis populares e centrais da política de xénero occidental. Aquí, Lewis reflexiona sobre o papel do feminismo radical dos anos setenta e o tratamento do xénero como unha falsa conciencia da violencia social promovida pola masculinidade. Lewis, pola contra, afirma que isto significou un claro rexeitamento á clase traballadora:

Para aquellas personas que tenían que vender sus cuerpos marcados por el género en el mercado laboral como estibadoras, secretarias, camareras, prostitutas, o bailarinas de cabaret, el género era una expresión corporal de la vida cotidiana que no podía ser debatida políticamente y descartada como algo simplemente falso (p. 40).

Dentro desta argumentación, Lewis continua para discutir os razoamentos tránsfobos dos colectivos TERF (Trans-Exclusive Radical Feminism, Feminismo Radical Trans-Exclusivo), o que lle serve para reflexionar sobre a relación dicotómica ou dialóxica entre o sexo e o xénero social.

Unha vez presentadas as discusións sobre o xénero ó público marxista, Lewis continua o capítulo asentando as bases e raíces teóricas do pensamento político marxista e o significado do capitalismo. Lewis define o capitalismo como "un sistema impersonal - como un conjunto operativo, no es inmoral sino más bien amoral” (p. 50); que non está avariado senón que "funciona de acuerdo con sus propias leyes" (p. 50); que é extractivo, en especial coa "fuerza de trabajo como mercancía" (p. 50), e empobrece á maioría social; e, que a súa fin só virá "por medio de [unha] intervención política deliberada" (p. 51). Con estes conceptos chave claros, Lewis percorre diferentes premisas do pensamento marxista (a orixe do capitalismo, o fluxo do capital e a extracción da plusvalía) dun xeito claro, amábel pero profundo que permite ó público queer e feminista comprender as bases económicas marxistas.

No remate deste primeiro capítulo, Lewis defende e adecúa o pensamento de Marx dentro das perspectivas queers sobre o xénero e a sexualidade. Este é unha das grandes pontes analíticas que resolve a autora entre o mundo marxista e o mundo queer. Lewis defende que a epistemoloxía marxista, por moito que algúns nostálxicos do conservadorismo socialista e comunista non o queiran asumir, non se basea na identidade senón na posición que ocupan as persoas dentro das relacións económicas e materiais que xorden: as persoas non son entes inmóbeis e permanentes "sino que son puntos conscientes que se mueven y cambian dentro de un sistema" (p. 67). Con isto, a autora non propón unha lectura postestruturalista dos postulados marxistas (como propoñen Laclau e Mouffe), mais tenta recuperar a fluidez e os fluxos do capital na análise económica de Marx para acomodalos á teoría social e ós movementos de diversidade sexual e de xénero.

Acomodada a fluidez e a flutuación como bases teóricas da análise social marxista, Lewis desprega unha relectura queer, marxista-feminista e trans-inclusiva da teoría da reprodución social (p. 122). É, neste segundo capítulo, onde a autora é capaz de establecer e configurar unha crítica anticapitalista ás estruturas heteronormativas ó mesmo tempo que evita caer no simplismo da condena directa a calquera institución social, política e de xénero vixente. É dicir, a través da análise marxista-feminista-queer de Lewis amósase como foron cambiando as relacións de xénero e as 
familias segundo os sistemas de produción e económicos que imperaban en cada un dos momentos da historia. A autora propón pensar a(s) familia(s) non como unha institución fixa, heterosexual e capitalista, senón como unha resposta ós fluxos sociais que dependen da estrutura económica. Así, a subversión da familia non se le como algo inherentemente anticapitalista nin feminista senón que depende das relacións socioeconómicas nas que se produzan. A postura da autora dálle a esquerda política unhas ferramentas teóricas e analíticas para volver a incluír á familia dentro do proxecto de emancipación social ó mesmo tempo que reivindica unha renovación e transformación plural e fluída das relacións sexuais, afectivas e de xénero inscritas na institución familiar (p. 139 en adiante). Así, a loita de clases inclúese como unha ferramenta para a consecución dun mundo máis xusto para as mulleres e as persoas queer e trans, do mesmo xeito que a loita contra a misoxinia e o heterosexismo son imprescindíbeis para a política marxista (p. 207).

Seguindo coa idea de non esquecer as estruturas materiais e económicas nas análises feministas e queer, Lewis utiliza o último dos capítulos centrais do libro para criticar a perspectiva interseccional (ou, como ela denomina, de vectores) por comprender que a raza, o xénero, a relixión ou a nación son liñas de opresión que se cruzan no corpo dun suxeito individual. Pola contra, Lewis afirma que estas son "relaciones sociales condicionadas por el capitalismo y que se condicionan unas a otras" (p. 217, a cursiva é da autora). A autora, que cita en varias ocasións o traballo de Jasbir K. Puar, Terrorist Assemblages: Homonationalism in Queer Times (2007, Duke University Press), propón entender os sistemas de opresión como o racismo, o sexismo ou o nacionalismo como ensamblaxes de relacións sociais e materiais influídas e influenciadas polo sistema económico nas que estas relacións están inscritas. Con esta nova perspectiva (post-)materialista marxista, Lewis pretende evitar unha política e análise crítica que se basee no sentimentalismo individualista onde os suxeitos acumulan opresións sen comprender e observar como estas se configuran e se establecen no contexto material, político e económico.

Deste xeito, a autora aspira a levar as formacións políticas dende un nacionalismo queer cara unhas propostas políticas baseadas no marxismo queer. É dicir, o entendemento de que as economías mundiais, as súas historias e as relacións materiais de produción inflúen, afectan e son afectadas polas relacións sociais de xénero, sexuais, étnicas, raciais, etc. Ó final, esta é a idea principal que Lewis tenta despregar durante todo o libro: a influencia das relacións económicas na produción social de identidades. Será, polo tanto, con esta idea coa que o libro remata a través dun decálogo de dez axiomas que sexan capaces de establecer un futuro marxista queer. 0 futuro que nos propón Lewis é un futuro baseado na solidariedade dentro dunha clase obreira que nos inclúa a todes e non só ós obreiros brancos. Unha solidariedade dialéctica e relacional que rexeite os binarismos e aposte por un feminismo trans-inclusivo, así como que politice as relacións sexoafectivas e queerice as análises económicas. É a creación dun mundo para todes.

En definitiva, cunha escritura áxil e unha posición política e teórica fortemente traballada, o libro é difícil de criticar. A súa perfecta estrutura cunha introdución teórica a cada un dos campos de aproximación (marxismo, feminismo e teoría queer) fai que a lectora se atope de súpeto dentro dunha conversa e análise reflexiva que amosa como as relacións capitalistas son produtoras das relacións sexuais e de xénero. Faise, polo tanto, unha reconstrución da vida social e económica que fai imposíbel discernir se as ferramentas analíticas utilizadas parten da corrente marxista, feminista ou queer. No libro, Lewis é capaz de mesturar e configurar alianzas teórico-políticas fortes e capaces de loitar e combater os poderes capitalistas e heterosexuais. Neste senso, o texto é de vital importancia non só para a investigación crítica, marxista e feminista senón tamén para 
o público xeral interesado na creación de alianzas políticas xustas e duradeiras dentro dos seus barrios, aldeas ou vilas. 